\title{
A Survey of Confucius Studies in China Today
}

\author{
LI QIQIAN
}

In late 1986 I wrote a paper with the same title, ${ }^{1}$ summarizing the situation of Confucius studies between 1979 and 1986. In the past three years great changes have taken place so I have updated the information in order to provide an overall and systematic understanding of the situation in the field.

\section{The General Situation}

With the progress of time, new trends and features have been appearing regularly in Confucius studies. The major points are as follows:

\section{Atmosphere of Mutual Respect}

A new atmosphere of mutual respect has emerged in the academic circles. Since the Third Plenary Session of the Eleventh Central Committee, a good situation of "letting a hundred flowers blossom and a hundred schools of thought contend" has arisen in the academic circles. In this process, however, some scholars were at odds with one another because of their different viewpoints thereby hindering normal research activities. When scholars realized how harmful this was, they all paid attention to strengthening solidarity. Some invited each other to attend the same conferences, some paid visits to each other, and some learned societies made clear their purpose and main theme from the very beginning of their foundation saying "We cherish academic freedom and equality, advocate the spirit of tolerance and appreciate such an attitude that 
'Although I do not agree with your viewpoints, I do firmly protect your right to express your opinions.' Learning and friendship are the only ties that join the members of the society." ${ }^{2}$ Through all these efforts, scholars holding different viewpoints and coming from different learned societies could respect one another and listen to the other side's criticisms with an open mind. This gave a good solution to the problem of discord and furthermore promoted the unfolding of academic activities.

\section{Regular Conferences}

Large-scale international conferences are convened regularly. After the Third Plenary Session of the Eleventh Central Committee, many academic conferences on Confucius have been convened; the scales of these conferences have been expanded. To be sure none of the conferences before 1986 were international. Since 1987, however, a host of international conferences have been held. For example, in September 1987, the China Confucius Foundation (Zhongguo Kongzi Jijinhui) and Singapore held a symposium in Qufu with participants from 12 countries. In October of the same year, the Chinese Association of Confucius Research (Zhonghua Kongzi Yanjiusuo) organized another conference in Jining which international scholars also attended. In November 1987, an "International Conference on Confucianism" was held in Taiwan. In October 1988, the China Confucius Foundation and the Konrad Adenauer Stiftung of the Federal Republic of Germany jointly held a conference in Bonn with participants from many countries. In October 7-10, 1989, the China Confucius Foundation convened an Academic Symposium on Confucius' 2540th Birthday in Beijing and Qufu. This was a high-level and large-scale international conference. During the conference, general secretary Jiang Zemin of the Chinese Communist Party Central Committee received some delegates from foreign countries and from both sides of the Taiwan Straits. This gave great impetus to the study of Confucianism. In October 12-16 of the same year, Qufu Teachers University held a "Colloquium on Confucius, Confucianism and the Contemporary Society." At this conference, Chinese and foreign scholars thoroughly discussed academic problems of immediate importance. This had a great influence on raising the level of academic studies. 


\section{Research Organizations and Learned Societies}

Research organizations and learned societies are established regularly. The issue of Confucius has aroused the attention of the whole society. In order to make Confucius research become a regular practice and carried out in a more planned way, different areas in China have established many research organizations and learned societies. As far as I know, the learned societies established before 1986 are: The China Confucius Foundation, The Chinese Association of Confucius Research, The Shandong Association of Confucius (Shandong Kongzi Xuehui), and The Shanxi Association of Confucius (Shanxi Kongzi Xuehui). The research organizations established in the same period are: The Institute of Confucius Research in Qufu Teachers University (Qufu Shida Kongzi Yanjiusuo), The Research Institute of Confucianism in Shandong Academy of Social Sciences (Shandong Shekeyuan Ruxue Yanjiusuo), the Research Institute of Traditional Culture in Shandong University (Shandong Daxue Chuantong Wenhua Yanjiusuo), and the Research Center of Chinese Thinkers in Nanjing University (Nanjing Daxue Zhongguo Sixiangjia Yanjiu Zhongxin). The learned societies established after 1987 are: The Association of Confucius Research of Suzhou City (Suzhou Shi Kongzi Yanjiuhui), the Confucius Association of Zhouzhi County, Shaanxi Province (Shanxi Sheng Zhouzhi Xian Kongzi Xuehui), The Research Association of Emperor Yan and Emperor Huang's Culture of Hunan Province (Hunan Sheng Yan Huang Wenhua Yanjiuhui), the Shandong Provincial Foundation of the Eastern Culture (Shandong Sheng Dongfang Wenhua Jijinhui), and the Black Bamboo Learned Society of Beijing City (Beijingshi Zizhu Xueshe). The research organizations established during the same period include among others the Research Center of Traditional Culture in East China Teachers University (Huadong Shida Chuantong Wenhua Yanjiu Zhongxin). The establishment of so many learned societies and research organizations within only a few years is without precedent in the past.

\section{Papers and Books}

Papers, collected papers, and books increase day by day. A total estimate of the amount of papers published before 1984 is not 
available, but there has been an increase in the amount of papers published after 1984. This can be shown by the number of papers included in the Index to Newspapers and Magazines Throughout the Country (Quanguo baokan suoyin). 1984 witnessed the publication of 68 papers on Confucius studies. There were 77 in 1985, 78 in 1986, 95 in 1987 and 92 in 1988. Except for the last year, during which there was a slight fall, there has been an annual increase in the number of published papers.

The number of collected papers and books officially published in recent years has also increased step by step. To my knowledge, there were four publications in 1984, eight in 1985, five in 1986, nine in 1987 and thirteen in 1988. Not only did the amount of publications increase gradually, but their academic value and the techniques of printing and binding were also gradually improved. In particular, the successive publication of the series of books entitled A Complete Collection of Works on the Confucian Culture (Kongzi wenhua da quan) by Shandong Province is indeed a big and new event in the publishing enterprise.

\section{Art and Literature}

Works of art come into being constantly and the image of Confucius is gradually presented on the stage and screen. One feature of Confucius studies in the past three years was that artists and literary writers increasingly took part in Confucius studies. They not only became prominent in the study of Confucius' thought on literature and language; what is more important, they created many works of art. For example, Shandong People's Publishing House published The Romance of Confucius (Kongzi yanyi) in 1985; the Cultural Bureau of Qingdao City composed and played a dance drama on Confucius named "Capriccio" in 1988; Shandong TV Station et al. wrote the TV series named "Confucius" and the Shanhua Press of Literature and Art published A Biography of Confucius (Kongzi zhuan). In addition, there are still other units and comrades who are currently compiling and writing various forms of scripts on Confucius. This kind of work was seldom seen in the past. 


\section{University Courses}

Many colleges and universities offer courses on Confucius' thought. To our knowledge, in recent years, such universities as Beijing Teachers University, East China Teachers University, Fujian Teachers University, Henan University, Qufu Teachers University, etc. all have begun to offer courses on Confucius' thought. Thus, Confucius studies have entered the classrooms of colleges and universities. During the Cultural Revolution, the issue of Confucius was much debated in colleges and universities, but there were only "ruthless criticism" and no scientific analyses at all at that time. The present task, however, is to analyze and study Confucius' thought calmly in order to reject the dross and assimilate the essence, inherit its excellent legacy and make it serve reality. This is a new aspect in Confucius studies.

\section{Expanding the Domain of Research}

Barriers are increasingly broken and the domain of research is enlarged. After the overthrow of the Gang of Four, explorations on various issues concerning Confucius began to appear. At the beginning, the papers published mostly centered on such traditional issues as the class-nature of Confucius' thought, Confucius' political thought, Confucius' view on God's will, Confucius' thoughts on education, benevolence, rites and eclecticism, the critical inheritance and historical role of his thought, etc. Soon afterwards scholars published their opinions on such new topics as Confucius' thoughts on economy, law, morality, psychology, logic, military affairs, food and drink, science of history, literature and music, archaelogical studies, Confucius and teaching and learning, Confucius' thoughts on physicial education and aesthetic education, Confucius and medical science, Confucius and the training of talented persons, Confucius' disciples, the Lu State and Confucius, new explanations to The Analects of Confucius (Lunyu), etc. These studies are in a matter of speaking all-embracing. In the recent two years, nevertheless, beside the continuous publication of papers on those topics, people have been paying more attention to the study of the question 
of the value of Confucius' thought in contemporary society. The issues that are of primary concern at the present are Confucius' ethical theories and the actual world, Confucius' thought on administration, Confucius' thought and the contemporary world, etc.

The comprehensive unfolding of Confucius studies is greatly related to the process of breaking down mental barriers.

\section{Confucius and the Gang of Four}

People have awakened from the miasma of "denouncing Confucius." In the two or three years just after the overthrow of the "Gang of Four," we would criticize them by saying that they "had pretended to criticize Confucius but actually revered him." In order to make a clean break with the Gang of Four we must put forward "the real criticism and denunciation of Confucius." It had seemed that Confucius was a person condemned by history was the final conclusion and that there should be no other discussion of this at all. Later on, we found out that the difference between us and the Gang of Four was not a matter of real or feigned criticism; instead, it was a matter of whether or not taking a scientific attitude towards Confucius. This change of attitude greatly benefited Confucius studies. It took place around 1979.

\section{The Forbidden Area of Ethics}

The forbidden area of ethics has been opened up. Since Lu Xun had epitomized the feudal ethical code as "a cannibal" and regarded Confucius as its founder, for a very long period of time the problem of ethics and morality put forward by Confucius was looked upon as a forbidden area. It had seemed that all the other issues about Confucius could be discussed and appraised, but the issue of his ethics and morality could only be regarded as "a cannibal" and no other understanding was possible. However, after 1981, discussions also took place on this issue. There was a viewpoint that the Confucian ethical code was not completely "cannibalistic"; it also had rational elements. Several papers were published during this time. Their major views were that in the Confucian ethical code, some elements are dross but some are still the essence of the national culture; some are to be criticized but some should be 
retained. After this forbidden area had been opened up, Confucius studies were carried on in a wider range.

\section{Confucius' Thought and Modernization}

The notion that Confucius' thought hinders the modernization process has been reconsidered. Confucius underestimated science and technology, advocated trust and the liking of things of the past; his thought lacks a spirit of initiative and an awareness of the importance of commodities and the idea of competition. Therefore his thought is "a grave obstacle that prevents China's development towards industrialization and modernization." This conclusion was acknowledged by the academic circles for a very long period of time. In recent years, however, people have challenged this understanding. There are mainly three factors that helped to provoke new points of view.

First, the Singaporeans have learned from their actual experience that Western morality has sunk into depravity and is not favorable to social stability. Li Guangyao has said, "Singaporeans are too Westernized so we must carry forward again the Eastern virtues to resist the corrosive influence of the decadent Western ideology."3 This made people think that the Confucian thought also is valuable in countries where economic modernization has already been realized.

Secondly, the economic hypervelocity growth of the Asian "four small dragons" where Confucius is much revered made international scholars ponder on the reason for this growth. In Herman Kahn's words: "The Confucian thought may be more valuable than the Western culture in promoting industrialization and moder-

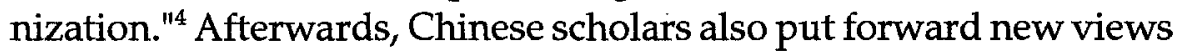
"Now that their [the four small dragons] economy has shown a high growth rate in terms of modernization, how can we assert that the Confucian thought is purely a negative factor that hinders the economic development and modernization process?"5 The scholars who raised such questions thought that Confucian thought could coincide with the modernization process.

Thirdly, people have started to pay more attention to the Confucian thought on administration. Administration includes: social administration, educational administration, business manage- 
ment, etc. It is easy for people to accept the idea that we can inherit certain Confucian views on social and educational administration. But how to use Confucianism in business management, is a new problem which is difficult to understand. In this respect, however, there are successful examples in Japan. Inase Iwao "gave considerable play to the application of Confucian thought in managing his business". .6 And to the TOYOTA enterprise, "Confucianism is of great importance as a traditionally revered way to do things". ${ }^{7}$ This challenged people's thinking. Since Confucian thought is of such great use to the modernized business management, we should acknowledge that it will also be of use in the contemporary society. Foreign scholars were the first to attach importance to this problem. Now it has also caught people's attention in China. Thus the scope of Confucius studies has widened, deepened and obtained a more immediate importance.

\section{The Development of Research Methods}

Research methods have developed too. Any opinion, treatise, theory or science is now permeated with a specific guiding principle and analytic method as the means of understanding problems. In recent years, there have been the following developments in the methodology of Confucius research.

\section{Confucius and Kant}

Evaluating Confucius by the viewpoint and methods imbedded in Kant's theory of the conflict of two laws. The theory holds that two propositions can at the same time oppose each other and be true. This method is not new, but has only in recent years been used to analyze political thought. That is, politically we should both notice Confucius' conservative and backward side as well as his progressive side of sympathy for the people. At the first sight these two sides seem contradictory to each other, but at the same time they exist objectively. 


\section{Comparing Chinese and Western Culture}

Understanding the characteristics of Confucius' thought by comparing the Chinese culture with the Western culture. In exploring the differences between the Chinese way of thinking and the Western way of thinking, some said: "The Western commercial society is extrovert and open. Business needs expansion...; this causes the Westerners' extrovert state of mind." "The Chinese agricultural society is self-sufficient and closed...; this causes the Chinese introvert state of mind." "The Westerners engage themselves in outward explorations and 'ponder on the universe'," while "the Chinese engage themselves in inward explorations and 'ponder over man himself'." Westerners attach importance to seeking the cause-and-effect relationship of all things, while the Chinese pay attention to the self-cultivation of "examining oneself" and "being prudent in behaviour and speech even if one is alone." 8 Some have said: "the West emphasizes abstract logical inference; Chinese Confucianism stresses understanding by learning through concrete practice." ${ }^{\text {S }}$ Some also said: "Chinese philosophy takes man as its standard and shows a tendency of 'attaching importance to ethics'; Western philosophy takes nature as its standard and shows a tendency of 'attaching importance to cognition'. These differences can be traced back to Confucius' idea of 'benevolence' and Socrates' idea of 'knowledge'."10

In discussing relations between people, it has been said: "My view on the Western people is that they take 'the individual as the standard and the self as the centre'; the Chinese people are different in that they take 'ethics as the standard and attach importance to the other side'."11 The Chinese have a strong sense of the group, while the Westerners emphasize the individual. Confucius is wellknown as an ethicist.

In analyzing the characteristics of the different schools of thoughts in the world, some people have found that the Greeks primarily contemplate the ultimate basis of the world. Is the basis the atom or water or fire? Middle Eastern Christianity seeks to understand the problem of who has created the world and mankind, while Buddhism tries to predict man's situation after death. Confucius and the Confucianists neither pay attention to the question of the origin of man nor to the situation after man's death. 
Li Qiqian

Confucianism concentrates on how man should behave in society in order to be a human being.

Moreover, there are also scholars who try to understand Confucius by comparing him with the exponents of various schools of thought in pre-Qin times.

By these comparisons we have reached a thorough understanding of some aspects of Confucianism.

\section{The Study of Confucianism and "Interpretative Studies"}

"Interpretative studies" is a bordering discipline that has emerged in the West in recent years. If you use this method to interpret old texts it becomes clear that there are obvious intentions as well as vague and hidden "implications." Later generations should both recognize the obvious intentions and pay attention to the vague "implications." But you should notice that you cannot interpret fully the "implications" once and for all; as time goes by and the interpretor's level of understanding is raised you will have a more thoroughgoing understanding of the "implications." This means that the "implication" is not a close and invariable self-evident truth but a kind of intention that changes along with the advancing of times. Actually, the new "implications" tally with the discoverer's level of understanding. Thus, not only is the phenomenon that "I annotate the Six Confucian Classics" quite normal, but the phenomenon that "the Six Confucian Classics annotate me" also becomes inevitable and meaningful and coincides with the principles of "interpretative studies." The newly found "implications" will have both a historical as well as a modern significance. Recently, some scholars used the method of "interpretative studies" to study the Confucian orthodoxy and attained convincing results. ${ }^{12}$

\section{Confucianism and Educational Policy}

It has been said that when Confucius talks about "Let the people do, but do not let them know," his thought is not to keep the people in ignorance. The reason is that seen from the point of view of educational psychology, man's true feelings and his personality are of natural existence, which "exist without being known," rather than the result of an intensified consciousness. Take the question of "innocence" for example. When a person is told that he is innocent 
and he himself realizes this, is he then still "innocent"? Only unselfconscious "innocence" is pure "innocence." When a person is doing good deeds, he should do so naturally without thinking of them as good deeds and without demanding gratitude from other people. Confucius' thought that "let people do, but do not let them know" is a beautiful ideal but not "a policy of keeping people in ignorance. ${ }^{13}$

\section{Confucius Research and the Method of Systematization}

Systematization is a discipline about the composition and variation of systems, which emerged after the 1950s. It holds that any system is composed by more than two factors that are interrelated with and interact upon each other. The function of the system composed by these factors is not the sum of the functions of the original factors but a new entirety that has new functions. The new entirety is not invariable; instead, it changes constantly under the interaction of all the factors. Hence the following principles and methods are formed. That is, when one tries to understand things, one should pay attention to such principles as entirety, composition, levels, relatedness, dynamicness and sequence. In some papers these principles are used to analyze Confucius, holding that Confucius' study on benevolence has formed a system of thought which consists of such elements as blood ties as the basis, psychological principles, humanism and the character of each individual. "All these factors are interdependent, they interpenetrate and condition one another..., and form a very characteristic pattern of thought and cultural psychological system."

The characteristics of this system are not the sum total of the four component factors; instead, the system has got a kind of new feature - "practical reason." This "practical reason" "takes a calm, realistic and rational attitude, instead of using a certain kind of mystic fanaticism, to explain and handle things and the tradition; uses reason to guide, satisfy and control sexual desires instead of adopting ascetism to save or taking a laissez-faire attitude to give way to one's carnal desires; and seeks to attain a certain kind of balance between humanism and individualism instead of adopting nihilism towards others or egoism towards oneself." "This practical reason attaches paramount importance to reality and practice; that 
is, theoretically, it does not explore, discuss and debate those philosophical questions that are difficult to solve but thinks it unnecessary to carry out this kind of pure, abstract arguments." ${ }^{14}$

This system has both conservative propositions and rational elements. It both plays the role of hindering social progress and of encouraging people to immerse themselves in hard work and thus benefitting social progress. This kind of analysis is of great inspiration.

\section{Inheriting Confucius' Thought}

As how to inherit Confucius' thought, several methods have been put forward. The three leading ones are: the criticism and inheritance method, the abstract inheritance method and the "three-divisions method." The first two are already familiar to the public, but the last one was only recently put forward by Kuang Yaming. This "threedivisions method" holds, that the thoughts that directly served the ruling class of the feudal society must be criticized thoroughly, e.g. Confucius' thought on rites, loyalty, filial piety etc.; the thoughts that to a certain extent contain an idea of initiative should be analyzed and sorted out to make things of the past serve the present, e.g. Confucius' thought on having a large population, enriching them and giving them good education; and those thoughts that still contain a spirit of vitality and are of importance today should be kept and carried on, e.g. his opinion that "If you know something, say that you know it, but if you do not know it, simply admit your ignorance." This method, as well, has been criticized.

\section{Other Methods}

Some scholars have studied the problem of self-contradiction in Confucius' speeches and behaviour from the standpoint of social status and social role in sociology. The point in case is that a man has many roles to play in society. In his family, he plays the role of child to his parents, husband to his wife and father to his children; but in society, the roles he plays are far more complicated. The differences of these roles, status and characters decide the differences of the content of his speech and his ways of doing things. Hence the contradictory points of view in The Analects, e.g. the views on 
food and drinking, on honesty, etc. are not self-contradictions in thought, but the attitudes adopted in different roles on various occasions on the one hand, and different demands to persons of various status and character on the other, as e.g. to the duke, the minister, the father and the son. Yet other scholars use the accomplishments and methods found in archaeology, critical interpretation of ancient texts, philology, etc. to study Confucius and the paragraphs and sentences of The Analects. They also have achieved some results.

\section{Issues and Attitudes}

On the basis of thorough research, many issues have been basically settled or unanimously acknowledged.

The attitude towards Confucius is basically unanimous. That is, Confucius is neither regarded as a God nor as a devil, but as a human being. This attitude is neither one of reverence nor one of criticism, but one in which Confucius is regarded as an object of study. At the same time, most scholars agree that Confucius should not be affirmed or negated completely, but should be treated in an analytical manner.

\section{Common Understandings}

There are, on the whole, some common understandings of the characteristics of the thought of Confucius. For years, scholars have studied Confucius' thought from different angles and through different methods. Most scholars think that Confucius' thought has the following characteristics. First, Confucius did not advocate unrealistic theories but attached importance to the administration of the actually existing society. He put forward the following process of administering a country: cultivating one's moral character, running one's home, governing a state and bringing about great order across the land. Second, Confucius did not uphold might but attached importance to education in order to establish a moral system based on benevolence and love. Third, he did not go to extremes but attached importance to steadiness and stability, 
putting forward the philosophical notion of "eclecticism" featuring compromize. Fourth, he was not good at vying for political power but good at administering and stabilizing the society. He established the reformative political theory of "rites", whose main content was to safeguard the heritage. Fifth, Confucius upheld the achievements of the ancient emperors, attached importance to ancient books and records, and summed up the historical experiences. Sixth, he was enthusiastic in promoting education, and did his utmost to establish private schools. Furthermore, he created a complete system of educational thought, and made outstanding contributions in the sphere of education, which were without parallel at the time. The above-mentioned characteristics are commonly acknowledged and they will greatly benefit the further studies of Confucianism.

\section{Two Attitudes}

Concerning the attitude towards traditional culture, the overwhelming majority of scholars are of the same opinion. Some years ago, there existed two inappropriate attitudes towards Confucianism and traditional culture. One attlitude held that Confucianism and traditional culture were purely feudal and backward things and that they were spiritual shackles and cultural burdens. If China wished to advance, she had to negate and eliminate them thoroughly. At the same time this attitude sought to introduce a kind of "new view of the world" from the other side of the ocean in order to carry on a thorough reconstruction of the Chinese culture and make it completely Westernized. The other attitude held that "Confucianism and traditional culture were completely rational and could completely adapt to the needs of modernization ... hence they could without further change be used as the basic direction for the future development of Chinese culture. ${ }^{15}$ After discussing these two points of view the majority of scholars in the recent years have realized that they are both biased. The current standpoint is that Confucianism consists of both drosses and essences and can therefore neither be completely affirmed nor thoroughly negated; instead, we should use Marxism as a guiding principle in order to analyze and differentiate it properly; the best choice is critical inheritance. 


\section{Archeological Materials}

In sorting out and researching archaeological materials scholars have solved some problems which for years were topics of discussion. Whether Confucius studied and made-commentaries on The Book of Changes (Yijing) or not had been an endless issue. After a copy in silk of the "Xici" (a part of The Book of Changes) was excavated from the Han Tomb (a tomb of Emperor Wen's time in the Western Han Dynasty) at Mawangdui in 1973, it was arranged and studied by specialists. The results clearly showed that Confucius had read and arranged The Book of Changes because one chapter of the "Xici" entitled "Yao" records: "In his old age, Confucius liked The Book of Changes so much that it was always on his table when he was dwelling and it was always in his bag while he was travelling." In answering Zigong's questions, Confucius said: "I do not read The Book of Changes for using it to tell fortunes; instead, I read it because I like its language." And he also said: "People of later generations will probably doubt my purpose of reading the The Book of Changes." These archaeological materials provide enough evidence to prove the close relationship between Confucius and The Book of Changes. ${ }^{16}$

Kong Congzi and The School Sayings of Confucius (Kongzi jia yu) had long been regarded as "fake books." And in Confucius studies, the academic circles also regarded these books as being not worth studying. In 1973, eight books, copied on bamboo slips, were found in the Han Tomb at Bajiaolang, Ding County, Hebei Province. Among these, The Analects of Confucius, Mottoes of Confucianists (Rujiazhe yan), Duke Ai's Inquiries on the Five Justices (Ai gong wen wu yi) and Biography of Baofu (Baofu zhuan) are Confucian classics. Based on research it was argued that "the Mottoes of Confucianists copied on bamboo slips is similar to the present edition of The School Sayings of Confucius ... It seems that our understanding of the present edition of The School Sayings of Confucius should be reconsidered." ${ }^{17}$ It was also argued that these books were "the products of the learned tradition of Confucius' family in the dynasties of Han and Wei" and have a very high value as historical material. ${ }^{18}$

The settlement of these complicated matters is of great importance to the study of Confucianism. 
Li Qiqian

\section{New Annotations and Interpretations}

New annotations of the paragraphs and sentences in The Analects of Confucius have made encouraging progress. The annotation of The Analects has a history of more than two thousand years and the number of people involved is countless. The number of books included only in the Japanese Chronology of the Analects (Lunyu nianpu) amounts to more than three thousand. But is it true, then, that we have nothing new to say in annotating The Analects today? No! In recent years, new explanations to The Analects have yielded satisfactory results. The following are only a few examples.

Example one: a new interpretation of the first paragraph of The Analects: "Learning and reviewing what one has learned in good time." The whole paragraph runs as follows: "Confucius says, 'learning and reviewing what one has learned in good time, isn't that a great pleasure? Having friends coming from afar, isn't that delightful? Not complaining when others do not know of you, isn't that a gentleman's quality?'" Everyone is familiar with these three sentences. The explanations to them all through the ages have always been that often reviewing what one has learned is a great pleasure, etc., that these three sentences have independent meanings, and that there is no cohesion at all between them. Recently, however, a scholar has argued that such explanations do not tally with the original idea. His interpretations are that "learning" here does not refer to study but to theory or proposition; "in good time" does not mean often but era or society; "reviewing" does not mean reviewing in its literal sense but using; whose extended meaning here is adopting; and that the meanings of these three sentences are not isolated but coherent. That is to say, a person is very pleased if his own theory is adopted by society. Even if society does not adopt his theory, but many friends favour it and visit him one after another to discuss it with him, he also feels cheerful for that. Moreover, even if society does not adopt his theory and the people do not understand it, he still does not have grudges; with this kind of attitude, is he then not a gentleman? In my opinion, such an explanation is very plausible. 19

Example two: a new interpretation to a paragraph in the eleventh chapter of The Analects. The original text is: "Zigong asks: 'Between Zhuansun Shi and Bu Shang, who is better?' Confucius says: 
'Zhuansun Shi goes somewhat too far, but Bu Shang somewhat does not arrive'." Zhu $\mathrm{Xi}$ had the following annotation to this paragraph: "Zhuansun Shi has superb talents and magnificent ideas, but he likes to be very hypercritical; so he often overdoes things. $\mathrm{Bu}$ Shang is honest, conservative and narrow-minded; so he often underdoes things." This annotation had become an established view for more than one thousand years. However, after detailed studies scholars of our time discovered that "Although Zhuansun Shi has talents, Bu Shang's talents are much higher. Bu Shang is courageous and openminded, has the poise of the earlier Legalists and ... is not at all a narrow-minded person. So Zhu's annotation is unsuitable." What is the proper understanding then? One scholar's book holds that Zhuansun Shi likes to talk with people, is "familiar with anybody at first sight" and makes too many friends; so Confucius said "Zhuansun Shi goes somewhat too far." In contrast, Bu Shang only "likes to make friends with those whose talents are higher than his," does not want to associate with ordinary persons and accordingly has too few friends; so Confucius said "Bu Shang somewhat does not arrive." Confucius' words here refer specifically to the matter of making friends and not to anything else. Such an interpretation tallies with the actual situation..$^{20}$

Other examples. The new interpretations to such sentences as "Ji has the Ba Yi Dance [a royal standard of ritual dance performed by sixty-four dancers, which $\mathrm{Ji}$, a noble, was not supposed to use translator's note] at his court," "If you let the God anger, there will be no use to worship other gods," "Silently keep in mind the knowledge you have learned," "Make one's own hair and dress up by oneself" [a sign of becoming an adult - translator's note], "Let the people do things by themselves," "The political systems of the Lu State and the Wei State are the same just as brothers," "If one studies well, one can become a high-ranking official," "I want to carry out the system of rites of the Zhou Dynasty in the East," "Inequality rather than poverty is to be worried about," "Ranqiu flinches from difficulty, so I encourage him," etc. All call for deep thought and greatly benefit the deep-going studies on Confucius. ${ }^{21}$

We can see from the aforementioned facts that the interpretations of the paragraphs and sentences in The Analects resulted in important findings. 


\section{Some Problems}

Among the many problems which have been discussed in Confucius studies in recent years the following have caught people's attention.

\section{The Relationship Between Confucius' Thought and the Culture of the State of $\mathrm{Lu}$}

Confucius came from the State of Lu. His thought was formed in the particular social environment of that State and therefore has both the distinguishing feature of the time and the mark of the State of Lu. This being the case, relating Confucius' thought to the culture of the State of $\mathrm{Lu}$ in our investigation becomes an important way and method of understanding Confucius. The past two years have witnessed the publication of a series of papers that investigate this problem. ${ }^{22}$ This is really a new phenomenon in the academic circles.

These papers contain different points of view. Some hold that the culture of the State of $\mathrm{Lu}$ in fact was the culture of the Zhou Dynasty. It had already become conservative and backwards in the Spring and Autumn period. Living in this environment, Confucius inherited this kind of culture entirely, hence his thought is completely conservative and backwards. ${ }^{23}$ Others find that it is true that the culture of the State of Lu was mainly Zhou culture and Confucius inherited it; however, Confucius not only inherited the Lu culture but his thoughts on "benevolence," "choosing the able and virtuous persons," etc. exceeded the Lu culture and had great progressiveness. ${ }^{24}$ It is up to further dicussion to decide who is right and who is wrong.

\section{The Study of Confucius' Disciples}

Many of Confucius' words were said to his disciples and many of his activities were done together with them. Therefore, studying these disciples becomes an important aspect of studying Confucianism. In recent years, some scholars have explored this aspect. The year of 1986, for example, saw the publication of thirteen papers on this aspect. ${ }^{25}$ Later on, a monograph entitled Studies on Confucius' Disciples (Kongzi dizi yanjiu) was published. These publications contain many convincing points of view. For example, one view holds that the relations between Confucius and 
his disciples were not purely that of the teacher and the students, instead they formed a social group with its own system of organization, standards of right and wrong, forms of ceremony and economic income. The members were organized together without distinctions regarding family name and clan affiliation, social position, income and nationality. They constituted a new social cell. This new point of view is indeed reasonable and it is beneficial to the evaluation of Confucius.

\section{Three Stages of Confucius' Thought}

In the most recent years, scholars have noticed that Confucius' thought in its process of formation was obviously divided into two stages, with Confucius' age of fifty being the point of division. That is, in his early years Confucius attached importance to rites. He first learned and then taught the rites, and later on became a great master of rites and music. In the latter stage, when he was about fifty years old, he put forward and propagated the notion of "benevolence" and became a thinker of "benevolence." There are different opinions concerning how to analyze and evaluate this change. Some hold that Confucius' thought became more and more conservative after he turned fifty. But others find that Confucius' conception of "benevolence" put forward after his age of fifty exceeded the culture of Lu whose major contents were the rites of the Zhou Dynasty. This was very progressive, so that Confucius became more and more liberal after he turned fifty. The latter view has been widely accepted.

\section{The Relationship Between Traditional and Modern Culture}

Most scholars have realized that it is not proper to take either an entirely negative attitude or an entirely positive attitude towards this problem; instead, traditional and modern culture should be analyzed in different ways. Especially one position is of great inspiration. It holds that one should not make general decisions on carrying on or discarding traditional culture "not only because traditional culture has a dual nature of positiveness and negativeness, but also because, as an overall system, it contains several different sub-systems which have different values of reservation and are not to be lumped together. ${ }^{126}$ Furthermore, this position divides 
the overall system of Chinese traditional culture into six subsystems, i.e. "the institutional culture," "the ritual and conventional culture," "the scientific and technological culture," "the culture of implements," etc. Among these, most elements in "the institutional culture" should be negated, while most elements in "the culture of implements" can be regarded as positive. All the other sub-systems have both negative and positive elements and should be treated analytically and in different ways. Although these six traditional cultures cannot be completely separated they each have their own independent character. Their differences will also be present in the future ${ }^{27}$ To analyze the problem in such a way has greatly inspired other scholars.

\section{The Importance of Confucius' Thought in Contemporary Society} In the six sub-systems of the Chinese traditional culture, "the academic culture" is further divided into Confucianism, Mohism, Taoism, Legalism, Buddhism, studies of the Confucian classics, studies of historical science, studies of literature, etc. Confucius' thought and the Confucian theories occupy an extremely important position in the traditional culture. Therefore, the value of Confucius' thought in contemporary society becomes a matter of particular interest to the public. There are different viewpoints in the discussion on this problem. One point of view argues that Confucianism has no value at all in contemporary society. It can only serve as a negative example and must therefore be thoroughly negated and firmly criticized. A few years ago, in the literature and art circles and among the young generation, there were relatively more people who adopted this kind of attitude. However, the number of these people is now becoming smaller and smaller. Another point of view holds that Confucius is "a sage" and all his words are still useful today and that Confucianism is only to be carried on but not to be analyzed and criticized. Either at home or abroad, there is only a small minority of people who adopt this attitude. A third point of view claims that although there are many out-of-date things in Confucianism, there is also a considerable number of rational and excellent parts in it. These excellent parts still have a very high practical value in contemporary society and examples of successful applications are found in Japan, South Korea, 
Singapore and in the areas of Hong Kong and Taiwan. Now China has also started to pay attention to this problem. For example, one scholar said with an emotional sigh: "Confucianism is highly thought of in neighbouring areas but is scoffed at and cast aside in its birthplace. It is high time that this situation is changed. ${ }^{128}$ At the same time, some papers were published which started to investigate this problem. ${ }^{29}$ The themes of the two symposia on Confucius respectively sponsored and convened by China Confucius Foundation and Qufu Teachers University in 1989 were both "The Importance of Confucius' thought in the Contemporary Society." Both symposia received many papers and the attending scholars stated many valuable new opinions. The collected papers of the two symposiums will be published which certainly will further promote Confucius studies.

We can see from the preceding survey that the study of Confucius has expanded from the meeting-rooms of academic conferences to university classrooms and from the national to the international arena. The methodology of Confucius studies has developed and now covers more disciplines, the questions for study have shifted from general problems to more essential, more profound and more sensitive problems, and the research results are presented in many forms and not just in scholarly articles and books. In short, Confucius studies have entered a new era. In accordance with this situation, research institutions and organizations at all levels should make arrangements to carry out the research in a more planned way. Since the academic circles are the main forces of research, they should be the first to contribute. In my opinion, the academic circles should carry out research work from the following five aspects: 1) Sort out and annotate the relevant data and ancient books and records; 2) continue to probe into the history of the State of $\mathrm{Lu} ; 3$ ) continue to analyze and understand the original thoughts and deeds of Confucius and his disciples; 4) study the historical development of Confucianism; and 5) study the importance of Confucius' thought in contemporary society. These five aspects are mutually related and it will not do to exclude any one of them. One particular researcher 
or a certain period of time may lay particular stress on a certain aspect, but generally speaking, studies on these five aspects should progress simultaneously. We should not overemphasize one at the expense of the others. The points discussed in this paper are open to criticisms and corrections.

Translated by Liu Shisheng

Li Qiqian is Professor and Head of The Institute of Confucius Research, Qufu Teachers University.

\section{NOTES}

1 See Lishi Jiaoxue Wenti, No. 4, 1987.

2 See Kongzi Yanjiu, No. 4, 1988, p. 75.

3 Kongzi Yanjiu, No. 1, 1986, p. 118.

4 Herman Kahn, World Economic Development: 1979 and Beyond (London: Croom Helm, 1979).

5 Kongzi Yanjiu, No. 1, 1989, p. 26.

6 Ibid., p. 37.

7 Ibid.

8 See Qilu Xuekan, No. 5, 1987, p. 99.

9 Kongzi Yanjiu, No. 3, 1986, p. 99.

$10 \mathrm{Du}$ Shu, No. 5, 1986 p. 127.

11 Guangming Ribao, July 21, 1986.

12 See "Lun rujia daotong de shiyi xue tezheng ji luoji," (On the interpretative character and logic of the Confucian orthodoxy), Fudan Xuekan, No. 5, 1988.

13 See Baike Zhishi, No. 2, 1989.

14 Ibid., p. 407.

15 See Zhexue Yanjiu, No. 4, 1989, p. 15.

16 See Kongzi Yanjiu, No. 4, 1988, p. 23.

17 See Kongzi Yanjiu, No. 2, 1987, p. 61.

18 Ibid., p. 64.

19 Qilu Xuekan, No. 6, 1986.

20 See, the parts on "Bu Shang" and "Zhuansun Shi" in Kongmen Dizi Yanjiu.

21 Kongzi Yanjiu, No. 3, 1987, p. 122

22 See Dongye Luntan, No. 3, 1987; Qilu Xuekan, No. 6, 1987; Kongzi Yanjiu, No. 2, 1988; and Xueshu Yuekan, No.
10, 1987.

23 See, Dongyue Luntan, No. 3, 1987.

24 See Qilu Xuekan, No. 6, 1987.

25 "1986 nian Kong Meng yanjiu lunwen tiyao" (Abstracts of Papers on Confucius and Mencius Studies, 1986).

26 Kongzi Yanjiu, No. 4, 1988, p. 76.

27 Ibid.

28 Kongzi Yanjiu, No. 2, 1989, p. 19.

29 Kongzi Yanjiu, Nos. 1 and 2, 1989. 